\title{
Solution Blow Spinning and Obtaining Submicrometric Fi- bers of Different Polymers
}

\section{J González Benito*, J Teno, D Torres and M Díaz}

Department of Materials Science and Engineering, University Carlos III of Madrid, Spain

\begin{abstract}
Thermoplastic polymers with potential biomedical and electrical applications such as polyethylene oxide, PEO, polyvinylidene fluoride, PVDF, polyethylene-co-vinyl acetate, EVA were prepared by solution blow spinning, SBS, looking for the best processing conditions to obtain submicrometric fibers with highest homogeneity in terms of morphology. Fabrication was carried out by a commercial airbrush and a home-made automatic SBS device. The aim of this work was to optimize the SBS process for each of the polymer systems to get films in the form of mats formed by submicrometric fibers. In particular, the pressure of the ejecting gas, the feed rate of the polymer solution and the working distance was considered as the final influencing parameters on the materials morphology. SEM was used as the main technique to evaluate the effect of the processing conditions on the final morphology. The different morphologies obtained showed a directly dependence of between them and the processing conditions. Gas pressure, feed rate and working distance have a great influence in the fiber production, fiber diameter, and fiber diameter distribution.
\end{abstract}

\section{Keywords}

Solution blow spinning, PVDF, EVA, PEO

\section{Introduction}

Nowadays Solution Blow Spinning (SBS) process is becoming an easy method to produce in situ films from polymer solution [1]. It consists in ejecting a polymer solution by the action of a gas flow through concentric nozzles, which in turn allows quick solvents evaporation. This process usually produces non-woven mats formed by micro or even nanofibers. SBS was developed by Medeiros, et al. [1] and during the last years many authors are using this method as an alternative of electro spinning process. The reasons they state lie on that SBS does not need complex equipments nor applying a high electric field attaining high production of material in very short period of time [2].

Regarding recent publications SBS is being carried out using a commercial airbrush or SBS device manufac- tured at the research labs. Several authors using an airbrush $[3,4]$ have explained how the processing parameters affect the production of nano or microfibers. The use of a simple airbrush allows producing in situ wound dressing as was reported by Behrens, et al. [5], pointing that is easier to handle it than a SBS equipment. However, the feed rate cannot be well controlled with this system, so sometimes it can lead to nozzle obstructions [6]. On the other hand, several authors made their own SBS devices based on the Medeiro's, et al. patent [6-9]. The use of this kind of devices usually allows a better control of the processing parameters as the feed rate, gas pressure and polymer concentration. This variables may greatly influence the average fiber diameter as has reflected several studies $[10,11]$. Therefore, controlling the processing parameters opens a wide field of researching since is the way of optimizing the SBS process to finally obtain

*Corresponding author: J González Benito, Department of Materials Science and Engineering, University Carlos III of Madrid, IQMAAB, Av.de la Universidad 30, 28911 Leganés, Madrid, Spain, E-mail: javid@ing.uc3m.es

Received: April 01, 2017: Accepted: June 22, 2017: Published: June 24, 2017

Copyright: (c) 2017 Benito JG, et al. This is an open-access article distributed under the terms of the Creative Commons Attribution License, which permits unrestricted use, distribution, and reproduction in any medium, provided the original author and source are credited. 
morphologically tailored films of any soluble polymeric system.

In this work, the SBS processing conditions were studied to understand their final influence on the submicrometric morphology of so prepared films of several thermoplastic polymers with potential electric and biomedical applications. The first proposed candidate is Poly(ethylene oxide), PEO. It is one of the most common used polymers for biomedical applications as drug delivery. It has good flexibility; low toxicity, is water soluble and good biocompatibility. Besides, this polymer is one of the first polymers used in electrospinning and SBS process $[12,13]$.

The second candidate is polyvinylidene fluoride, PVDF. This polymer has electro active properties like pyro, piezo-electricity, is highly chemically resistant and biocompatible [14-17]. Furthermore, PVDF mats obtained from SBS and electro spinning processes, have been just reported, by several authors [18-20].

The last polymer under study is poly(ethyl-co-vinyl acetate), EVA. This copolymer when the composition is $40 \%$ by weight in vinyl acetate presents an acceptable mechanical strength taking into account their extremely elastic behaviour. Besides, EVA has good barrier properties and is biocompatible. Due to this, EVA is widely used in the agro-alimentary industry and food packag-

Table 1: Proportions of solvents and polymers in the solutions used to prepare the materials.

\begin{tabular}{|l|l|l|}
\hline Polymers & Solvent proportion & $\begin{array}{l}\text { Polymer } \\
\text { concentration }\end{array}$ \\
\hline PVDF & (Acetone/DMF) 9:1 & $11 \% \mathrm{wt}$ \\
\hline EVA40 & (Chloroform/Dimethylcloride) 5:5 & $7 \% \mathrm{wt}$ \\
\hline PEO & (Acetone/Chloroform) 5:5 & $6.67 \% \mathrm{wt}$ \\
\hline
\end{tabular}

ing. EVA has a dielectric strength and volume resistivity that allows using it in low and medium voltage applications $[21,22]$. EVA has been previously fabricated by electro spinning by authors like Alhusein, et al. [23-25], also the present authors previously have studied this material fabricated by SBS [26].

\section{Experimental}

\section{Materials}

Polyvinylidene fluoride, PVDF ( $\mathrm{Mn}=107,000$ and $\mathrm{Mw}=275,000$, pellet grade), Poly(ethylene oxide), $\mathrm{PEO}$ $(\mathrm{Mv}=100,000$, powder $)$ and Poly(ethylene-co-vinyl acetate), EVA (\%VA = $40 \mathrm{wt} \%$, melt index $57 \mathrm{~g} / 10 \mathrm{~min}$, $190{ }^{\circ} \mathrm{C} / 2.16 \mathrm{~kg}$ ) were supplied by Sigma-Aldrich. The solvents used were N, N-Dimethylformamide (DMF), Chloroform (purity 99.5\%), Dimethylchloride (anhydrous, purity 99.8\%) and Acetone (HPLC purity 99.9\%) all of them analytical reagents, used as received and supplied by Sigma-Aldrich.

\section{Materials preparation}

The proportions of solvents and polymers in the solutions used to prepare the materials are shown in Table 1. To produce the PVDF and EVA samples a home-made SBS equipment was used (Figure 1a). This equipment was inspired in the work of Medeiros, et al. [1]. It is composed by a nozzle connected to an air compressor with a pressure regulator and a plastic syringe coupled in an automatic pump (NE $1000 \mathrm{X}$, New Era System, Inc., Farmingdale, NY). The nozzle is made by an aluminium tube (inner diameter $0.7 \mathrm{~mm}$ ) perforated to introduce the pressurized air and crossed along by a glass tube (inner diameter 0.5 ) which is positioned so it protruded $2 \mathrm{~mm}$ beyond the

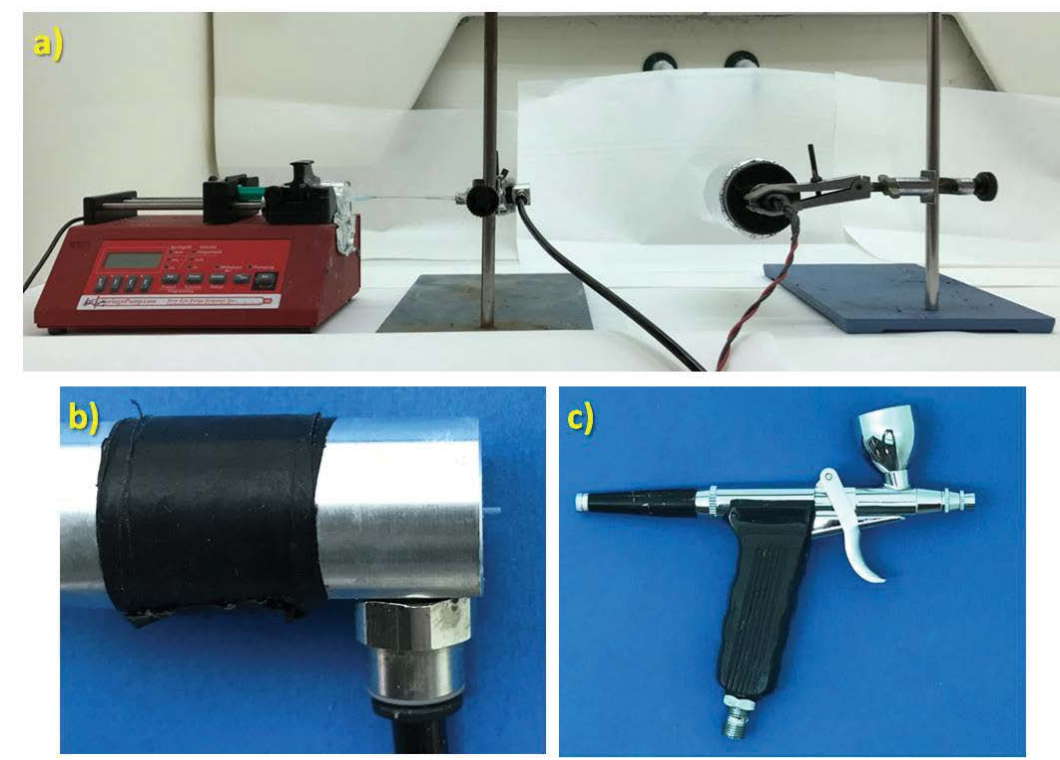

Figure 1: a) Handmade SBS equipment; b) Nozzle of the SBS equipment; c) Airbrush. 
Table 2: SBS processing conditions when preparing the PEO system.

\begin{tabular}{|l|l|l|l|}
\hline Code & Feed rate $(\mathbf{m l} / \mathbf{m i n})$ & WD $(\mathbf{c m})$ & Pressure (bar) \\
\hline PEO1 & Gravitacional feed & 10 & 2 \\
\hline PEO2 & Gravitacional feed & 15 & 2 \\
\hline PEO3 & Gravitacional feed & 10 & 4 \\
\hline PEO4 & Gravitacional feed & 15 & 4 \\
\hline PEO5 & Gravitacional feed & 10 & 6 \\
\hline
\end{tabular}

Table 3: SBS processing conditions when preparing the PVDF system.

\begin{tabular}{|l|l|l|l|}
\hline PVDF Conditions & \multicolumn{2}{l|}{} \\
\hline Code & Feed rate (ml/min) & WD (cm) & Pressure (bar) \\
\hline PVDF1 & 0.5 & 10 & 4 \\
\hline PVDF2 & 0.25 & 10 & 4 \\
\hline PVDF3 & 0.1 & 10 & 4 \\
\hline PVDF4 & 0.075 & 10 & 4 \\
\hline PVDF5 & 0.5 & 10 & 1 \\
\hline PVDF6 & 0.5 & 10 & 2 \\
\hline PVDF7 & 0.5 & 10 & 3 \\
\hline PVDF8 & 0.5 & 5 & 4 \\
\hline PVDF9 & 0.5 & 15 & 4 \\
\hline PVDF10 & 0.5 & 20 & 4 \\
\hline PVDF11 & 0.5 & 15 & 2 \\
\hline PVDF12 & 0.5 & 20 & 2 \\
\hline
\end{tabular}
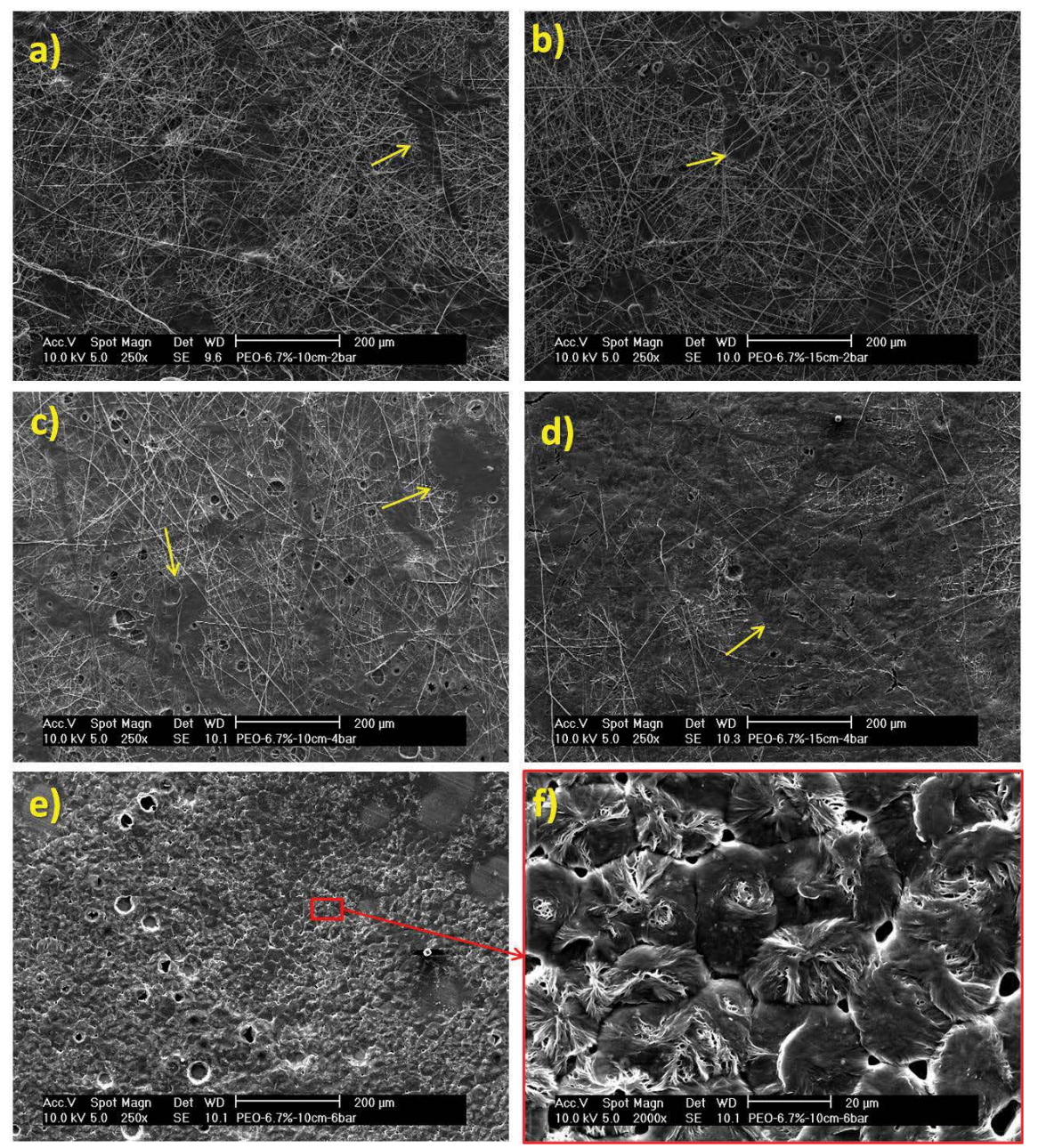

Figure 2: a) PEO1; b) PEO2; c) PEO3; d) PEO4; e) PEO5; f) details of the spherulites formed in sample PEO5. 


\section{Techniques}

Morphology analysis for PEO and EVA samples was carried out using a Phillips XL30 and an acceleration voltage of $10 \mathrm{kV}$. PVDF samples were inspected using a TENEO Field Emission Scanning Electron Microscope, FESEM (FEI), with an acceleration voltage of $2.0 \mathrm{kV}$. In every case samples were gold coated using a low vacuum coater Leica EM ACE200.

Fiber diameter measurements were carried out by image analysis using Image J Software. To facilitate the measurements, three straight lines were drawn in the left, right and centre regions of the selected images. All crossed fibers by theses draw lines were measured. With this method a representative number of measurements were done.

Diameter measurements in the PVDF were performed on images at $\times 500$ magnifications, EVA samples were measured at $\times 200$ magnifications, and PEO fibers were measured at $\times 8000$ magnification.

\section{Results and Discussion}

\section{PEO}

Effect of gas pressure: Figure $2 \mathrm{a}$, Figure $2 \mathrm{c}$ and Fig- ure 2e show, the SEM images of blow spun PEO films obtained using three different pressures, 2, 4, and 6 bar respectively. As the pressure increases the images show a decrease in the amount of fibers with regions even fibers as if a simple cast film was obtained [6]. At high enough pressures turbulence in the air flow can be produced, so the spinning jet cannot be formed. The late means that solution droplets does not have time to become nanofibers, therefore the solution drops are dragged directly to the target [27]. In these cases therefore it is expected a polymer crystallization similar to that occurring in a cast film, as can be seen in the Figure $2 \mathrm{f}$ in where a detail of PEO spherulites are observed.

Regarding the fiber diameter values shown in Table 5 and Figure 2c, an increase of them is obtained at higher pressure (Figure $2 \mathrm{a}$ and Figure $2 \mathrm{~b}$ ). This phenomenon occurs because of a local decrease of the temperature pro-

Table 5: Fiber diameters of all PEO samples.

\begin{tabular}{|l|l|l|}
\hline & Average diameter $\mathbf{( n m})$ & Standard deviation $(\mathbf{n m})$ \\
\hline PEO1 & 351.3 & 213.4 \\
\hline PEO2 & 642.9 & 474.8 \\
\hline PEO3 & 460.7 & 198.4 \\
\hline PEO4 & 606.4 & 390 \\
\hline
\end{tabular}

c)
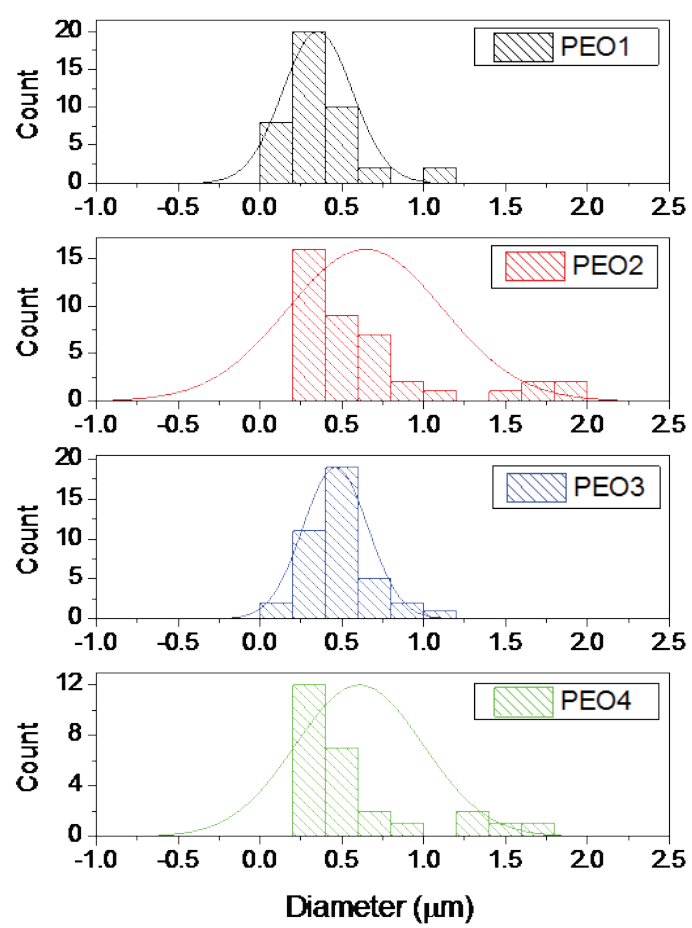

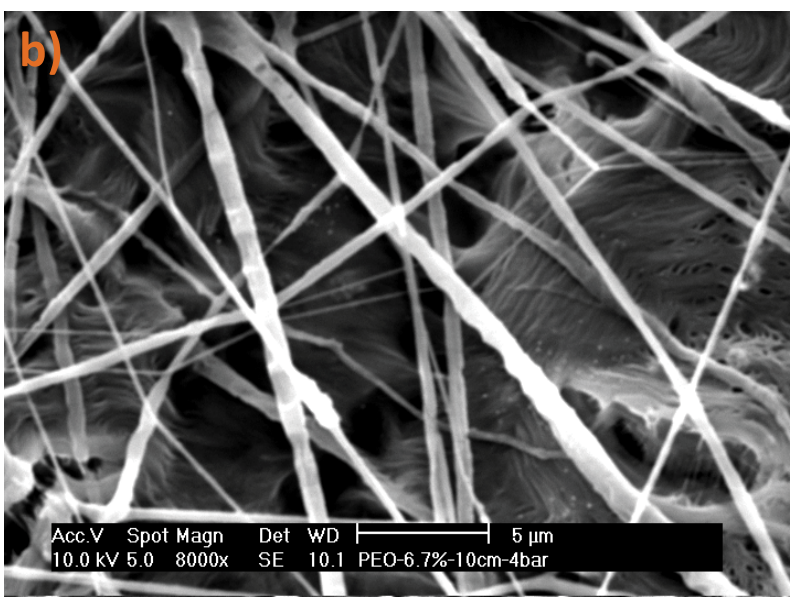

Figure 3: a) SEM Image ( $\times 8000)$ of PEO2; b) SEM Image (x8000) of PEO3; c) Plot of diameter distribution of all samples. 
portional to the gas expansion, due to the high pressure of the gas. It means a poor solvent evaporation leading to higher probability of fiber coalescence between wet fibers and therefore higher diameter final fibers $[5,8,27]$.

Effect of working distance: Considering the two pressures ( 2 and 4 bar), fiber spinning was studied as a function of the working distance (Figure 2a, Figure 2b, Figure $2 \mathrm{c}$ and Figure $2 \mathrm{~d}$ ). It can be seen that at 4 bar there exists more and larger plane regions (like a cast film) when the working distance increases. The same result is observed in the previous section. So, it seems that the optimal pressure to obtain nanofibers is at 2 bars. Comparing the two samples at low pressure (Figure $3 \mathrm{a}$ and Figure $3 b$ ) it is easy to see more fiber production when the target is farther away the nozzle. It might be explained if it is considered that the polymer solution spend more time in the air flow, leading to an easier solvent evaporation [28-30].

Taking into account the fiber diameters, it can be seen in the Table 5 and Figure $3 c$, that in all samples is possible to find nanometric fibers. However, the fiber diameter and the average diameter extracted from the diameter distributions increase when the working distance increases. The wide diameter distribution at lon-

ger working distances can be explained considering that different solvent evaporation times occurred during the fibers fly. But, the diameter increase is difficult to understand although it can be due to the fibers welding and fiber-drops coalescence.

\section{PVDF}

Effect of feed rate: The feed rates studied were from 0.02 to $0.5 \mathrm{ml} / \mathrm{min}$ (Table 3). In Figure 4, the samples morphology as a function of feed rate is presented [31]. It can be seen that the density of fibers is lower the slower feed is. This result is pointing out that with $0.5 \mathrm{ml} /$ min of feed rate the fiber production obtained is higher being in accordance with other experimental results [8]. A possible reason is that slow rates may lead to jet instability because polymer droplets cannot be properly extruded by the shear gas forces [32]. Thus, regions similar to those obtained by simple casting and bundles are

Table 6: Fiber diameters of PVDF samples as function of feed rate.

\begin{tabular}{|l|l|l|}
\hline & Average diameter $\mathbf{( n m})$ & Standard deviation $\mathbf{( n m})$ \\
\hline PVDF1 & 624.9 & 284.4 \\
\hline PVDF2 & 592.1 & 244.7 \\
\hline PVDF3 & 633.9 & 325.5 \\
\hline PVDF4 & 593.6 & 350.1 \\
\hline
\end{tabular}
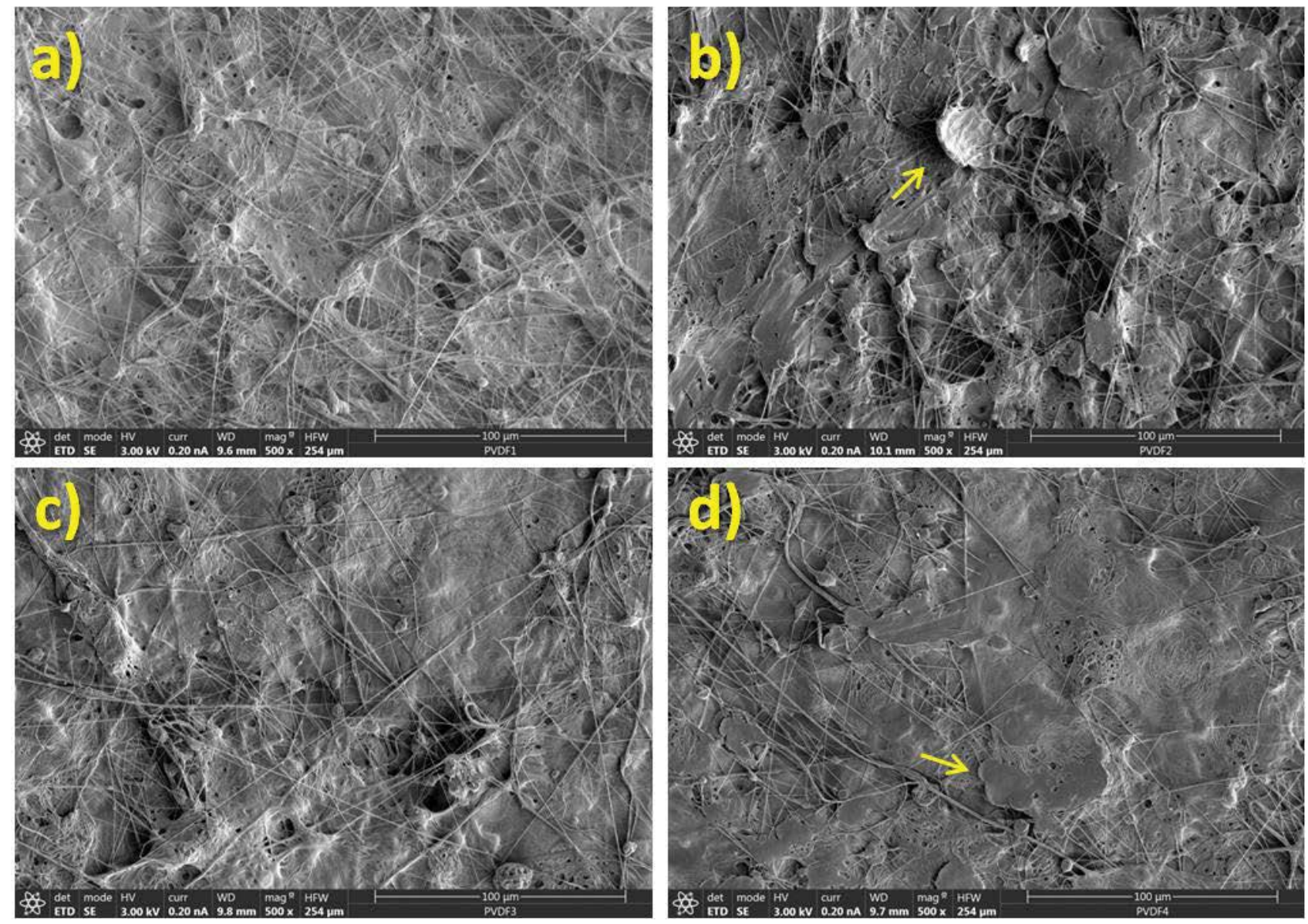

Figure 4: SEM images of SBS PVDF using different feed rates (Table 3): a) PVDF1; b) PVDF2; c) PVDF3; d) PVDF4. 
increased at slow rates. This kind of morphologies were well explained by several authors $[2,3,33]$. On the other hand, the feed rate does not seem to exert any influence on the fiber diameters at least under the other conditions of 4 bar for the ejecting gas and $10 \mathrm{~cm}$ of working distance (Table 6).

Effect of gas pressure: The next step in the optimization of the SBS process for producing PVDF was the study of the effect of the ejecting gas pressure when the feed rate and the working distance are set at $10 \mathrm{~cm}$ and $0.5 \mathrm{ml} / \mathrm{min}$ respectively. Figure 5 clearly shows that there is poorer fiber production when 2 and 3 bars of pressure are used (Figure $5 b$ and Figure $5 c$ respectively) instead of using 1 bar of pressure (Figure $5 \mathrm{a}$ ). In fact both samples show the very similar morphology, they are basically based on welded fiber bundles, roller beads and large smooth regions similar to those obtained by simple solvent casting.
However as can be seen in Figure $4 \mathrm{a}$ when the pressure is increase up to 4 bars again more fiber production is obtained. On the other hand, in terms of fibers diameter an opposite tendency is observed; there is an increase of average diameter when the gas pressure is increase until 4 bars of pressure is used for which the average diameter of the fibers produce decreases (Figure 6a). Besides, the distribution of fiber diameters tend to be narrower the thinner the fibers (Figure 6b) being in accordance with other results obtained by Oliveira, et al. [8].

Effect of the working distance: Figure 7 shows SEM images of SBS PVDF samples obtained at different working distances. In all cases the fiber formation is too poor being most of the surface covered by beads of polymer. This result may be attributed to short solution time of fly in relation the evaporation rate. But, comparing sample fabricated at $10 \mathrm{~cm}$ (Figure $4 \mathrm{a}$ ) with samples at 15 and 20
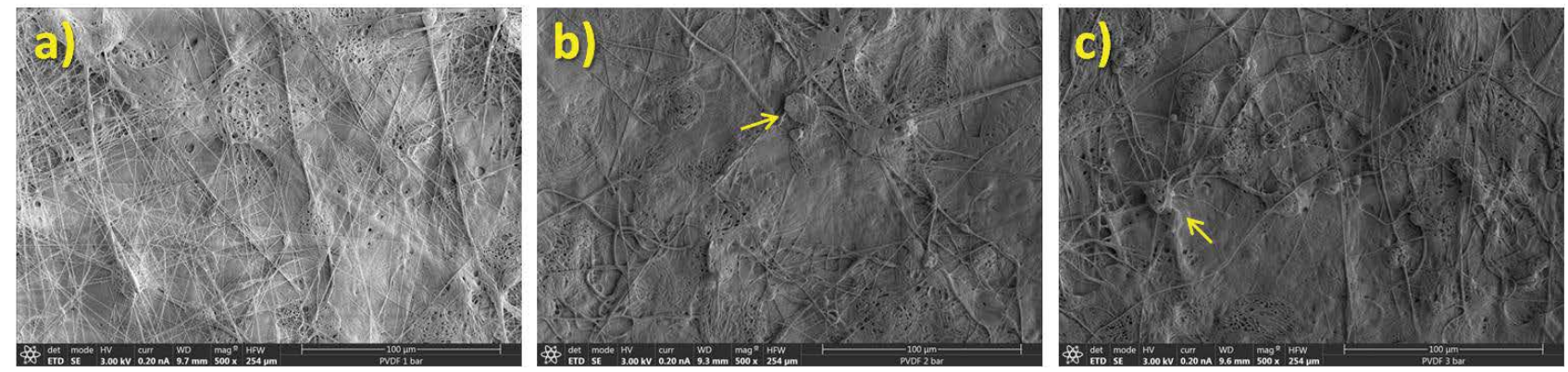

Figure 5: SEM images of SBS PVDF using different ejecting gas pressure (Table 3): a) PVDF5; b) PVDF6; c) PVDF7.
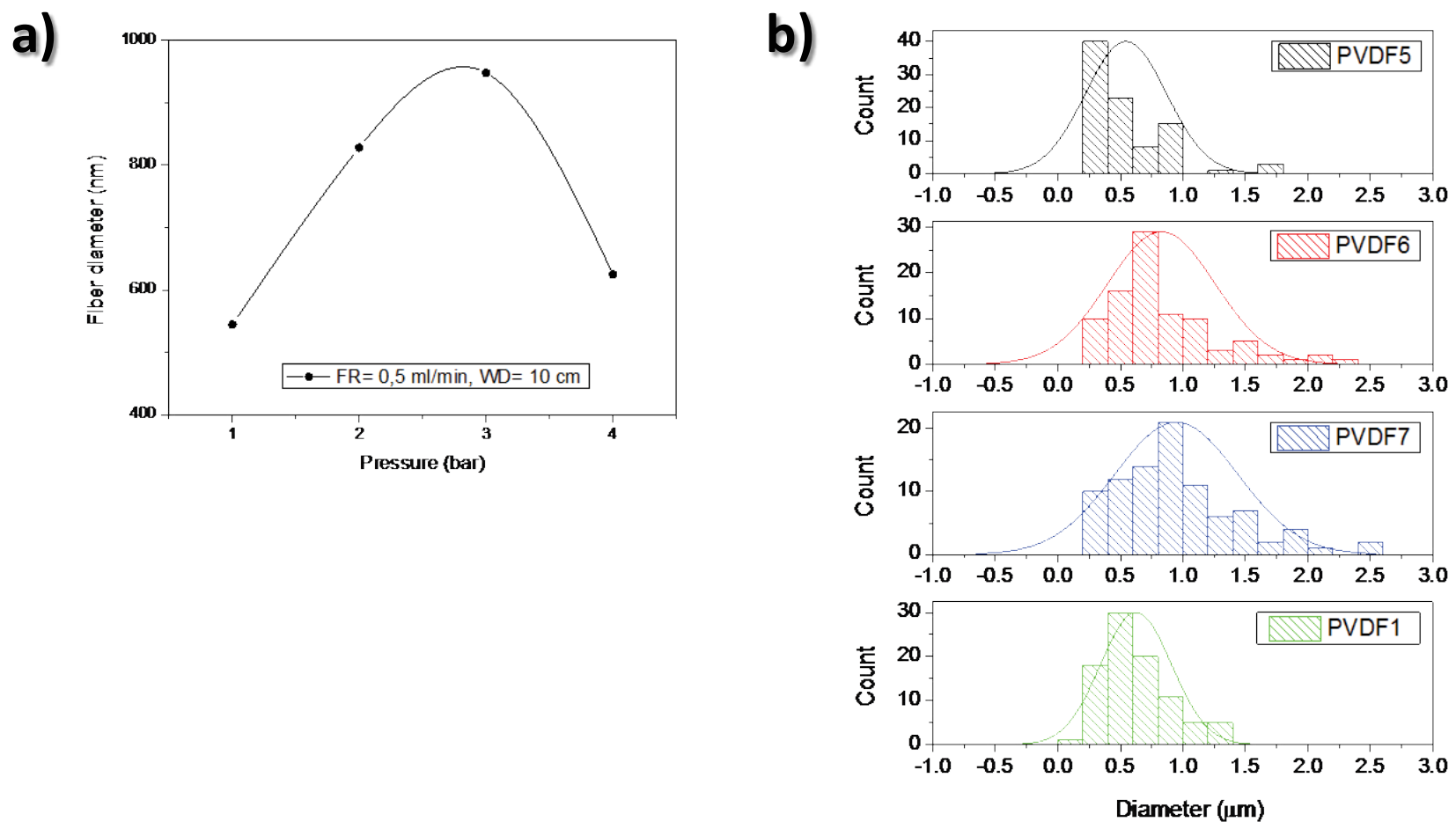

Figure 6: a) Fiber average diameter as a function of ejecting gas pressure; b) Distribution of fiber diameters at different gas pressures. 
$\mathrm{cm}$ (Figure $7 \mathrm{~b}$ and Figure $7 \mathrm{c}$ respectively), fiber formation decreases when $10 \mathrm{~cm}$ is overlapped. It may be consider that more time of flight implies more fiber welding, bundles and roller bead formation.

Effect of parameter combination: The aim of this section is study how simultaneous changes in ejecting gas pressure and working distance affect the PVDF fiber formation. Samples was prepared using 2 bars at different working distances while feed rate was maintained at $0.5 \mathrm{ml} / \mathrm{min}$. Figure 8 shows the SEM images with their respective diameter fibers distribution. Comparing both images with sample at 2 bar (Figure $5 b$ ) big differences are found. When the highest working distance is employed, fiber formation decreases drastically. It is meaning the formation of fibers coalescence, rolling beads, and welded fibers-bundles, as heterogeneous film. Seems morphology is also well found when higher pressure is used, as is above commented for sample at 4 bar and 20 $\mathrm{cm}$ (Figure 7c).

Table 7: Fiber diameters of EVA samples.

\begin{tabular}{|l|l|l|}
\hline & Average diameter $(\boldsymbol{\mu m})$ & Standard deviation $(\boldsymbol{\mu m})$ \\
\hline EVA1 & 2.71 & 1.77 \\
\hline EVA2 & 3.41 & 1.85 \\
\hline EVA3 & 2.31 & 1.09 \\
\hline EVA4 & 2.19 & 1.37 \\
\hline
\end{tabular}

However when near distance is used (Figure 5b), bad fiber formation is founded. It can be solvent evaporation during the fly that is low for pressure at 2 bars. Nevertheless, sample prepared at $15 \mathrm{~cm}$ (PVDF11) shows a well fiber formation with a good fiber distribution. Also bundles shapes are well observed linking the fibers.

\section{EVA}

Two processing parameters have been studied to optimize the SBS process for preparing EVA films, feed rate and pressure of ejecting gas as reported in previous works $[8,30]$. In particular, in this section gas pressure and fluid rate as a function of working distance were evaluated. Figure $9 \mathrm{a}$ and Figure $9 \mathrm{~b}$ show the morphology of samples prepared at 2 bars of gas pressure, $0.5 \mathrm{ml} / \mathrm{min}$ of feeding rate, and 15 and $20 \mathrm{~cm}$ as working distances respectively. On the other hand, Figure $9 \mathrm{c}$ and Figure $9 \mathrm{~d}$ show morphologies of the EVA samples prepared using $0.5 \mathrm{bar}$ of gas pressure, $0.25 \mathrm{ml} / \mathrm{min}$ of feeding rate, and 15 and $20 \mathrm{~cm}$ as working distances respectively. In terms of working distance, regardless the gas pressure and the feeding rate, there is a decrease in the number of beads and simple canting-like regions for the higher working distance.

The combination of a feed rate of $0.5 \mathrm{ml} / \mathrm{min}$ with
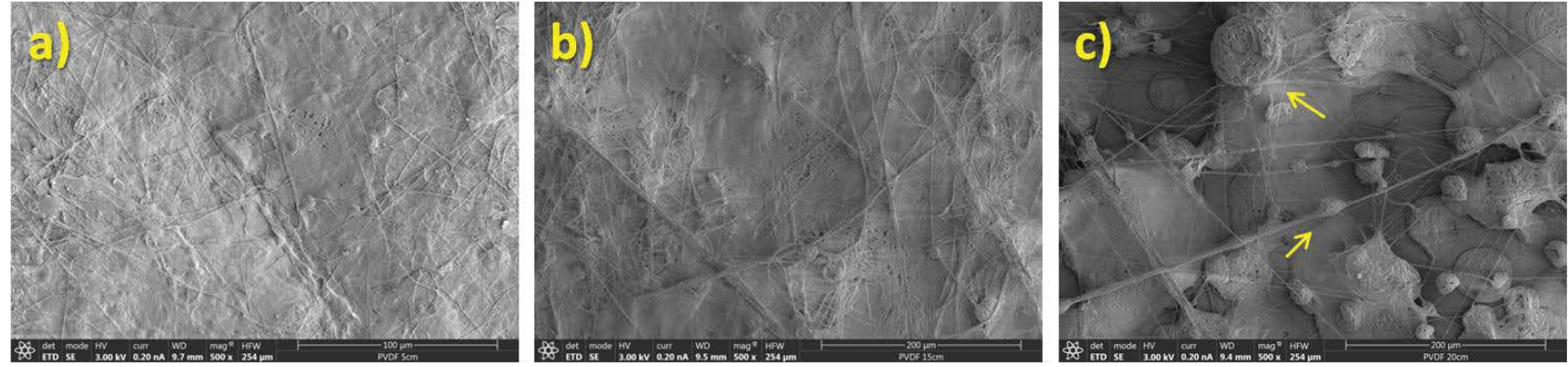

Figure 7: SEM images of SBS PVDF using different working distance (Table 3): a) PVDF8; b) PVDF9; c) PVDF10.
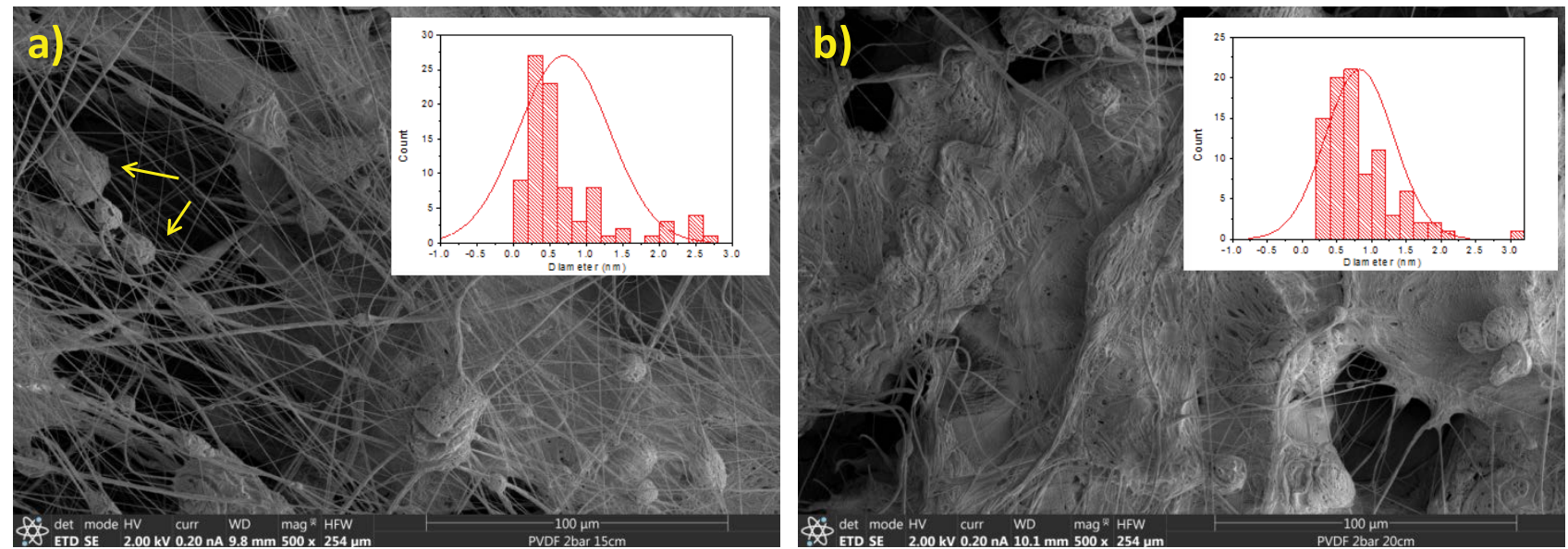

Figure 8: SEM images of SBS PVDF using 2 bars, $0.5 \mathrm{ml} / \mathrm{min}$ and different working distances (Table 3): a) PVDF11; b) PVDF12. 

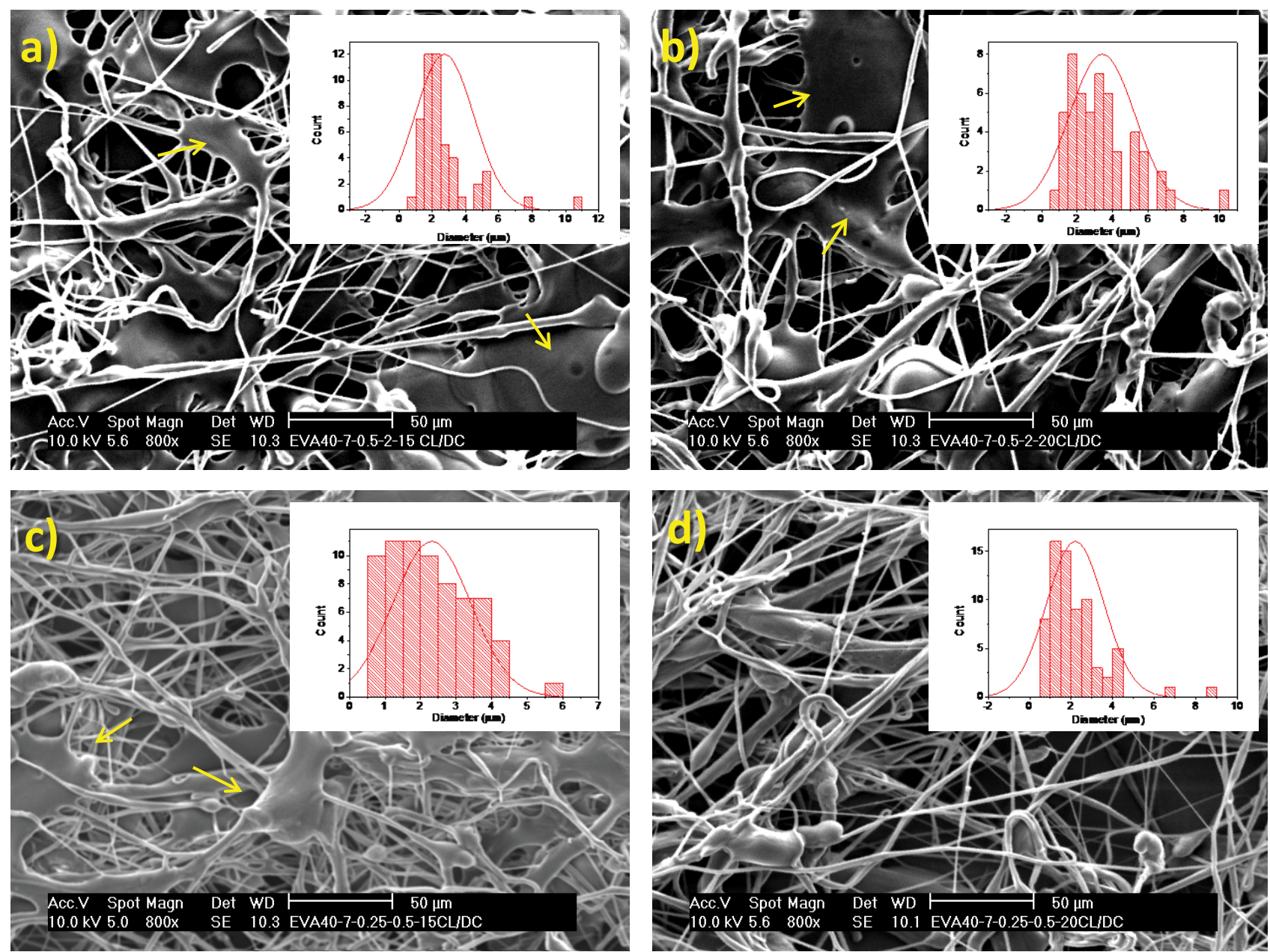

Figure 9: SEM images of SBS EVA using different processing conditions (Table 4): a) EVA1; b) EVA2; c) EVA3; d) EVA4. Diameters distributions are shown as inserts.

pressure at 2 bars shows fibers over large regions with morphology similar to a simple cast EVA (EVA1 and EVA2). This result seems to be due to a slow solvent evaporation, probably because the ejecting gas pressure used is not enough to remove the solvent and get a good spinning jet. Besides, it seems that the used feeding rate is quite fast leading to the production of droplets instead of fibers at that pressure. However, the combination of a feed rate of $0.25 \mathrm{ml} / \mathrm{min}$ and a gas pressure of 0.5 bars shows a completely non-woven mats with some fiber bundles (EVA3 and EVA4). It seems to be that using low pressure and low feed rate an optimal equilibrium in microfibers formation is obtained.

Comparing fiber average diameters it can be said that they are higher at the highest working distance considered in this work for the highest pressure considered, as can be seen for the sample EVA2 (Figure 9 and Table 7). This phenomenon is similar to that previously commented for the PVDF system. In the case of low pressure and low feed rate (EVA3 and EVA4), little changes were observed as a function the working distances used, only that associated to the fiber production.
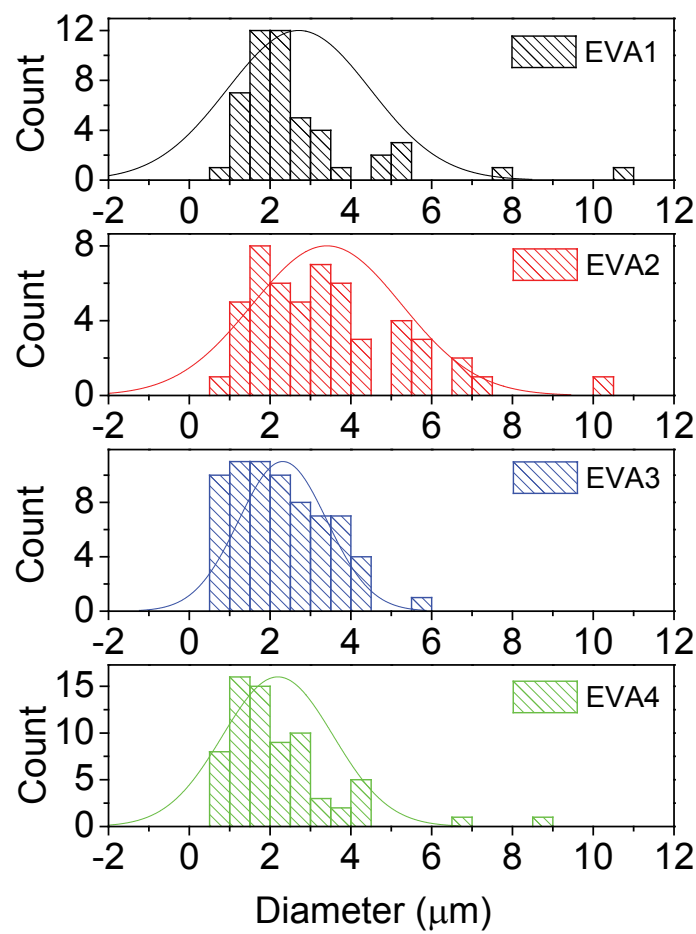

Figure 10: Plot of fiber diameter distribution of EVA samples. 
Finally, in Figure 10 it is shown narrower fiber diameter distribution for samples at low pressure and feed rate (EVA3 and EVA4), being the opposite behaviour when higher pressure and feed rate were used (EVA1 and EVA2). Again, this result can be explained as it was done for the PVDF system.

\section{Conclusions}

The solution blow spinning, SBS, process has been revelled as a good method to prepare submicrometric fibers of PEO, PVDF and EVA polymers. By simply varying a few set conditions in the SBS process to optimize the fabrication of mats of the polymers considered is possible. In the case of the PEO polymer only when the pressure of the ejecting gas is low enough, 2 bars, a material formed by a randomly distributed submicrometric fibers is obtained, reducing the average diameter of the fibers at shorter working distances. On the other hand, for the PVDF, the best fiber mat formation is obtained when high feed rate, intermediate pressure and a medium working distance is employed. Finally, for EVA with a $40 \%$ of vinyl acetate the optimal mat film formation occurs using low feeding rates and pressures of the ejecting gas so as relatively long working distances.

\section{Acknowledgements}

Authors gratefully acknowledge financial support from the Projects MAT2014-59116-C2 (Ministerio de Economía y Competitividad); 2012/00130/004 (Fondos de Investigación de Fco. Javier González Benito, política de reinversión de costes generales, Universidad Carlos III de Madrid) and 2011/00287/002 (Acción Estratégica en Materiales Compuestos Poliméricos e Interfases, Universidad Carlos III de Madrid).

\section{References}

1. Eliton S Medeiros, Gregory M Glenn, Artur P Klamczynski, William J Orts, Luiz HC Mattoso (2009) A Solution blow spinning: A new method to produce micro- and nanofibers from polymer solutions. J Appl Polym Sci 113: 2322-2330.

2. MM Wojasinski, M Pilarek, T Ciach (2014) Comparative studies of electrospinning and solution blow spinning processes for the production of nano fi brous poly (L-lactic acid) materials for biomedi- cal engineering. Polish Journal of Chemical Technology 16: 43-50.

3. W Tutak, S Sarkar, S Lin Gibson, TM Farooque, G Jyotsnendu, et al. (2013) The support of bone marrow stromal cell differentiation by airbrushed nanofiber scaffolds. Biomaterials 34: 2389-2398.

4. A Abdal Hay, AS Hamdy, KA Khalil, JH Lim (2015) A novel simple one-step air jet spinning approach for deposition of poly(vinyl acetate)/hydroxyapatite composite nanofibers on Ti implants. Mater Sci Eng C Biol Appl 49: 681-690.

5. AM Behrens, BJ Casey, MJ Sikorski, KL Wu, W Tutak, et al. (2014) In situ deposition of PLGA nanofibers via solution blow spinning. ACS Macro Lett 3: 249-254.
6. W Tutak, G Gelven, C Markle, XL Palmer (2015) Rapid polymer fiber airbrushing: Impact of a device design on the fiber fabrication and matrix quality. J Appl Polym Sci 132.

7. ES Medeiros, GM Glenn, AP Klamczynski, WJ Orts, LHC Mattoso (2014) Solution Blow Spinning.

8. JE Oliveira, EA Moraes, RGF Costa, AS Afonso, LHC Mattoso, et al. (2011) Nano and submicrometric fibers of poly(D,L-lactide) obtained by solution blow spinning Process and solution variables. J Appl Polym Sci 122: 33963405.

9. RGF Costa, GS Brichi, C Ribeiro, LHC Mattoso (2016) Nanocomposite fibers of poly(lactic acid)/titanium dioxide prepared by solution blow spinning. Polymer Bulletin 73: 2973-2985.

10. G Sabbatier, P Abadie, F Dieval, B Durand, G Laroche (2014) Evaluation of an air spinning process to produce tailored biosynthetic nanofibre scaffolds. Mater Sci Eng C Mater Bio Appl 35: 347-353.

11. DD da Silva Parize, MM Foschini, JE de Oliveira, AP Klamczynski, GM Glenn, et al. (2016) Solution blow spinning parameters optimization and effects on the properties of nanofibers from poly(lactic acid)/dimethyl carbonate solutions. J Mater Sci 51: 4627-4638.

12. YW Cho, JH Park, SH Kim, YH Cho, JM Choi, et al. (2003) Gentamicin-releasing urethral catheter for short-term catheterization. J Biomater Sci Polym Ed 14: 963-972.

13. JE Oliveira, Ea Moraes, JM Marconcini, LHC Mattoso, GM Glenn (2013) Properties of poly(lactic acid) and poly(ethylene oxide) solvent polymer mixtures and nanofibers made by solution blow spinning. J Appl Polym Sci 129: 3672-3681.

14. R Costa, C Ribeiro, AC Lopes, P Martins, V Sencadas, et al. (2013) Osteoblast, fibroblast and in vivo biological response to poly(vinylidene fluoride) based composite materials. J Mater Sci Mater Med 24: 395-403.

15. P Martins, AC Lopes, S Lanceros-Mendez (2014) Electroactive phases of poly (vinylidene fluoride) Determination, processing and applications. Prog Polym Sci 39: 683-706.

16. R Gregorio, EM Ueno (1999) Effect of crystalline phase, orientation and temperature on the dielectric properties of poly (vinylidene fluoride) (PVDF). J Mater Sci 34: 4489-4500.

17. YK Low, X Zou, YM Fang, JL Wang, WS Lin, et al. (2014) $\beta$-Phase poly(vinylidene fluoride) films encouraged more homogeneous cell distribution and more significant deposition of fibronectin towards the cell-material interface compared to $\alpha$-phase poly(vinylidene fluoride) films. Mater Sci Eng C Mater Biol Appl 34: 345-353.

18. X Liu, T Lin, J Fang, G Yao, H Zhao, et al. (2010) In vivo wound healing and antibacterial performances of electrospun nanofibre membranes. J Biomed Mater Res A 94: 499-508.

19. X Zhuang, L Shi, K Jia, B Cheng, W Kang (2013) Solution blown nanofibrous membrane for microfiltration. J Memb Sci 429: 66-70.

20. J Gonzalez Benito, J Teno, G Gonzalez Gaitano, S Xu, MY Chiang (2017) PVDF/TiO2 nanocomposites prepared by solution blow spinning: Surface properties and their relation with S. Mutans adhesion. Polym Test 58: 21-30. 
21. R Coles, D McDowell, MJ Kirwan, D McDowell (2003) Food Packaging Technology. CRC Press, USA.

22. JK Fink (2010) Handbook of Engineering and Specialty Thermoplastics: Polyolefins and Styrenics. John Wiley \& Sons, New Jersey, United States.

23. N Alhusein, IS Blagbrough, PA De Bank (2012) Electrospun matrices for localised controlled drug delivery release of tetracycline hydrochloride from layers of polycaprolactone and poly(ethylene-co-vinyl acetate). Drug Deliv Transl Res 2: 477-488.

24. N Alhusein, PA de Bank, IS Blagbrough, A Bolhuis (2013) Killing bacteria within biofilms by sustained release of tetracycline from triple-layered electrospun micro/nanofibre matrices of polycaprolactone and poly(ethylene-co-vinyl acetate). Drug Deliv Transl Res 3: 531-541.

25. SL Shenoy, WD Bates, HL Frisch, GE Wnek (2005) Role of chain entanglements on fiber formation during electrospinning of polymer solutions: good solvent, non-specific polymer-polymer interaction limit. Polymer 46: 3372-3384.

26. J Teno, G Gonzalez-Gaitano, J Gonzalez-Benito (2017) Poly (ethylene-co-vinyl acetate) films prepared by solution blow spinning: Surface characterization and its relation with E. coli adhesion. Polym Test 60: 140-148.

27. HF Lifeng Zhang, Perry Kopperstad, Michael West, Nyle Hedin (2013) Generation of Polymer Ultrafine Fibers
Through Solution (Air-) Blowing. Polym Compos 21: 449456.

28. AMC Santos, ELG Medeiros, JJ Blaker, ES Medeiros (2016) Aqueous solution blow spinning of poly(vinyl alcohol) micro- and nanofibers. Mater Lett 176: 122-126.

29. J Oliveira, GS Brichi, JM Marconcini, LHC Mattoso, GM Glenn, et al. (2014) Effect of solvent on the physical and morphological properties of poly(lactic acid) nanofibers obtained by solution blow spinning. J Eng Fiber Fabr 9: 117125.

30. H Lou, W Li, C Li, X Wang (2013) Systematic investigation on parameters of solution blown micro/nanofibers using response surface methodology based on box-Behnken design. J Appl Polym Sci 130: 1383-1391.

31. JL Daristotle, AM Behrens, AD Sandler, P Kofinas (2016) A review of the fundamental principles and applications of solution blow spinning. ACS Appl Mater Interfaces 8: 34951-34963.

32. L Zadorosny (2013) Producao e caracterizacao de micro e nanofibras de Poli (fluoreto de vinilideno) - PVDF obtidos pela técnica de Fiacao por Sopro em Solucao. Universidade Estadual Paulista.

33. H Lou, W Han, X Wang (2014) Numerical study on the solution blowing annular jet and its correlation with fiber morphology. Ind Eng Chem Res 53: 2830-2838. 